\title{
RECLASSIFICAÇÃO E QUANTIFICAÇÃO DA COBERTURA VEGETAL NATIVA DA BACIA HIDROGRÁFICA DO RIO BRILHANTE-MS
}

\author{
Patricia Silva Ferreira $^{(a)}$, Charlei Aparecido da Silva ${ }^{(b)}$ \\ (a) Doutoranda do Programa de Pós-Graduação em Geografia/Faculdade de Ciências Humanas, UFGD, Email: \\ patiferrera@gmail.com \\ (b) Docente do Programa de Pós-Graduação em Geografia/Faculdade de Ciências Humanas, UFGD, Email: \\ charleisilva@ufgd.edu.br
}

\section{EIXO: BACIAS HIDROGRÁFICAS E RECURSOS HÍDRICOS: ANÁLISE, PLANEJAMENTO E GESTÃO}

\begin{abstract}
Resumo
Há uma grande demanda por estudos que analisem a aplicação da Lei Federal 12.531/2012 relativa à conservação quantitativa de Reserva Legal (RL) no interior das propriedades rurais bem como a somatória delas no contexto da bacia hidrográfica. Neste sentido, este trabalho se propôs reclassificar os dados de vegetação, quantificá-los e analisá-los no âmbito da legislação ambiental, tomando como área de estudo a bacia do Rio Brilhante/MS. Para tanto, foi criado um banco de dados espaciais utilizando os programas ArcGis ${ }^{\circledR} 10.2$ e QGIS 2.18. Em 1984, o território da bacia era composto pelo Cerrado e pela Floresta Estacional Semidecidual. Em 2015 da área total da bacia, 82\% estavam antropizadas e $18 \%$ ainda eram ocupadas com vegetação natural. Se a bacia do Rio Brilhante fosse tomada como uma única propriedade rural, não cumpriria com o quantitativo de $20 \%$ exigido no Código Florestal Brasileiro.
\end{abstract}

Palavras chave: Vegetação; Geoprocessamento; Código Florestal

\section{Introdução}

A aprovação pela Câmara Federal do PL 1.876-C/99 que indicava a radical revogação da Lei Federal 4771/1965 - Código Florestal Brasileiro - para instituir um novo Código Florestal - Lei Federal 12.651/2012 (BRASIL, 2012) acarretou na legalização de passivos ambientais de toda ordem no território brasileiro. Segundo Gandolfi (2011) a Reserva Legal (RL) possibilita o uso sustentável da vegetação e constitui importante complemento às Áreas de Preservação Permanente (APP) contribuindo para a recarga dos mananciais e na conservação da biodiversidade.

A RL fornece diversos serviços ambientais, o que incrementa, sobremaneira a produção de grãos, alimentos e insumos no território, além da contribuição para a manutenção da biodiversidade, condições climáticas e qualidades do ar, solo e água (GANDOLFI, 2011).

Neste sentido o motidvo para a investigação e quantificação dos passivos ambientais relativos à RL na bacia hidrográfica do Rio Brilhante. Ao definir a bacia hidrográfica como unidade de análise 
ambiental a ser estudada, é possível reconhecer diversos elementos naturais que estão submetidos por uma determinada exploração econômica e um dado tipo de uso das terras.

As geotecnologias, principalmente os Sistemas de Informação Geográfica (SIG), sensoriamento remoto orbital e GPS (Sistema de Posicionamento Global) possibilitam meios e técnicas para tratamento das informações espaciais, permitindo visualizá-las em forma de mapas, relatórios e tabelas, constituindo ferramenta de análise e subsídio à tomada de decisão (SILVA e ZAIDAN, 2004).

Os mapeamentos do Macrozoneamento Geoambiental do Estado do Mato Grosso do Sul que serviu para identificação da vegetação nativa (primária ou secundária) no ano de 1984 e a as cartas do IBGE referente as informações de cobertua vegetal em 2015 - ambos os produtos produzidos numa escala de 1:250000 foram os principais subsídios para a reclassificação e quantificação pretendida.

A região centro-sul do estado de Mato Grosso do Sul, sobretudo na região da bacia hidrográfica do Rio Brilhante, apresenta uma carência de estudos que quantifiquem o uso e ocupação das terras, identificando a conservação da área, deste modo o presente trabalho teve por objetivo a reclassificação e quantificação da cobertura vegetal da bacia, por meio do uso das ferramentas de geotecnologias.

\section{Classificação da cobertura vegetal da bacia hidrográfica do Rio Brilhante}

Na região sul do estado do Mato Grosso do Sul além da presença do Cerrado, há relações fitogeográficas com o Chaco, Amazônia, Floresta Atlântica e Floresta Meridional, o que resulta em uma paisagem florística bastante diversificada. Os cerrados abrangem $65 \%$ da cobertura vegetal, as florestas semideciduais $8,9 \%$ e o Chaco 3,8\% (MATO GROSSO DO SUL, 2002).

Utilizando como referência o trabalho desenvolvido pelo IBGE (2012) - o Manual Técnico da Vegetação Brasileira e a classificação de Ribeiro e Walter (1998), as fitofisionomias consideradas para a bacia do Rio Brilhante podem ser subdivididas em, basicamente, duas categorias: Floresta Estacional Semidecidual e Cerrado.

A cobertura vegetal nativa dos municípios de Dourados, Itaporã, Maracaju, Sidrolândia, Ponta Porã, Rio Brilhante, Douradina, Angélica e Deodápolis revela o domínio da Floresta e do Cerrado, porém com o passar dos anos, essa vegetação natural foi sendo descaracterizada, como consequência das ações antrópicas a vegetação nativa foi reduzida a resquícios da Floresta Estacional Semidecidual e Cerrado, assim, atualmente a predominância é a agricultura e a pastagem plantada (MATO GROSSO DO SUL, 2011). 
XVII Simpósio Brasileiro de Geografia Fisica Aplicada

I Congresso Nacional de Geografia Física
OS DESAFIOS DA GEOGRAFIA FÍSICA NA FRONTEIRA DO CONHECIMENTO

Instituto de Geociências - Unicamp

Campinas - SP

28 de Junho à 02 de Julho de 2017

\subsection{Floresta Estacional Semidecidual}

O conceito ecológico da Floresta Estacional Semidecidual é estabelecido "em função da ocorrência de clima estacional que determina semideciduidade da folhagem da cobertura florestal. Na zona tropical, associa-se à região marcada por acentuada seca hibernal e por intensas chuvas de verão" (IBGE, 2012, p. 93). Essas florestas são constituídas por gêneros que expandiram suas espécies ao longo dos cursos de água, nascidos nos planaltos e nas serras cratônicas, que são os divisores das principais bacias hidrográficas brasileiras (IBGE, 2000, p. 59). São dois subgrupos de formações delimitadas para o Mato Grosso do Sul: Aluvial e Submontana, isso devido a descontinuidade desse tipo florestal e por estar sempre situada entre dois climas, um úmido e outro árido. Geralmente as áreas cobertas por esta floresta possuem solos férteis e têm grande relevância na economia regional (MATO GROSSO DO SUL, 2002).

A fim de facilitar o entendimento da distribuição espacial das formações fitofisionômicas abordadas, a Figura 1 apresenta o perfil esquemático das diferentes fitofisionomias da Floresta Estacional Semidecidual.

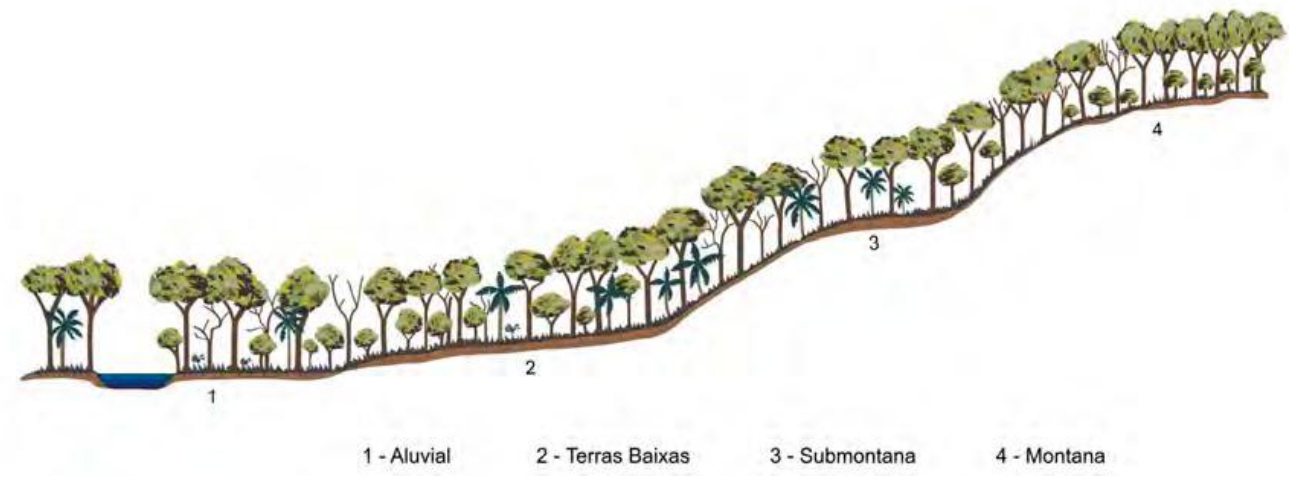

Figura 1 - Perfil de fitofisionomias da Floresta Estacional Semidecidual. Fonte: Veloso, Rangel Filho e Lima (1991) apud IBGE (2012, p. 96).

\subsection{Cerrado}

O Cerrado é caracterizado pela presença de invernos secos e verões chuvosos, é o tipo de bioma localizado em áreas onde predominam os latossolos. O mosaico vegetacional do Cerrado é influenciado diretamente pelo clima - que segundo Eiten (1994) tem efeitos sobre a vegetação -, pelas propriedades químicas e físicas do solo, pela disponibilidade da rede de drenagem e pela geomorfologia e relevo. A distribuição das fisionomias do Cerrado está vinculada a latitude, características do lençol freático, regularidade de queimadas e diversos fatores antrópicos, tal como a supressão de vegetação para atividades agropecuárias (RIBEIRO e WALTER, 1998). 


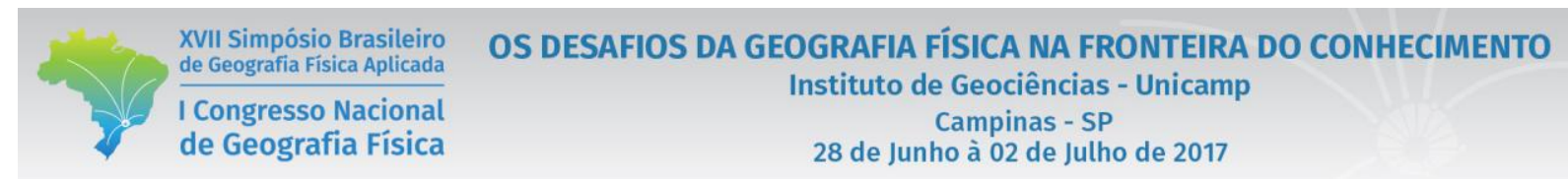

Em relação ao Cerrado restam apenas $32 \%$ da cobertura vegetal nativa no estado do Mato Grosso do Sul. A predominância são das fitofisionomias florestal (13\%) e campestre (17\%) da área total do Cerrado na porção estadual (MATO GROSSO DO SUL, 2002).

Existem dois sistemas de classificação de vegetação do Cerrado, o primeiro refere-se ao Manual Técnico da Vegetação Brasileira (IBGE, 2012) em que o Cerrado foi subdividido em quatro subgrupos de formação: Savana Florestada, Savana Arborizada, Savana Parque e Savana Gramíneo-Lenhosa (Figura 2). O segundo sistema proposto por Ribeiro e Walter (1998), indica a vegetação do Cerrado apresenta três tipos de fitofisionomias: as formações florestais que foram subdivididas em Mata Ciliar, Mata de Galeria, Mata Seca e Cerradão; as formações savânicas em Cerrado sentido restrito, Parque de Cerrado, Palmeiral e Vereda e as formações campestres comportam os subgrupos Campo Sujo, Campo Limpo e Campo Rupestre.

A classificação elaborada por Ribeiro e Walter (1998) é amplamente utilizada em estudos que envolvem análise de imagens de satélite e mais indicada para estudos locais ou regionais. Os dois sistemas de classificações apresentados demonstram certo grau de semelhança, porém considerando a escala da área de estudo, optou-se por adotar a classificação de Ribeiro e Walter (1998) para classificar o Bioma Cerrado da bacia hidrográfica do Rio Brilhante.

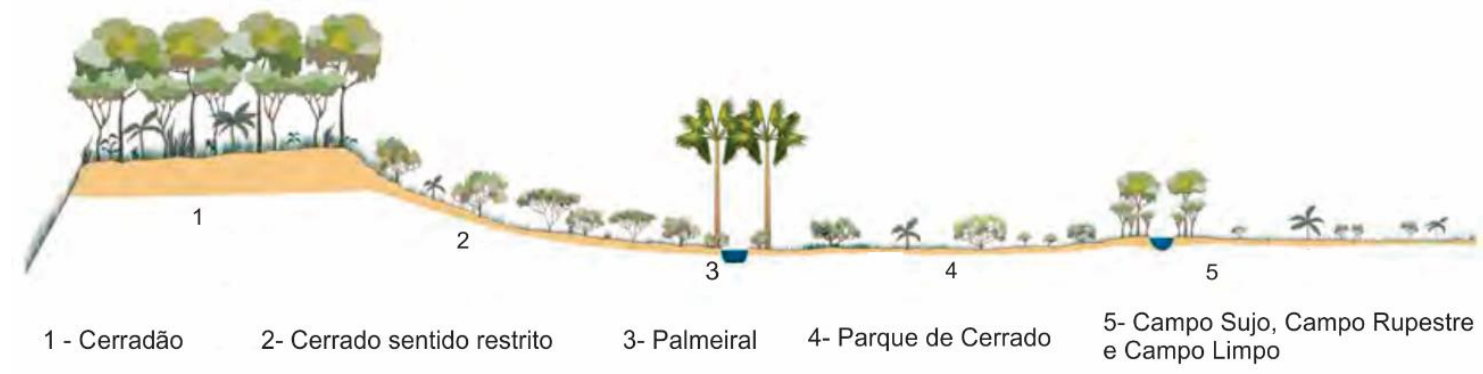

Figura 2 - Perfil das fitofisionomias do Cerrado.

Fonte: Adaptado de Veloso, Rangel Filho e Lima (1991) apud IBGE (2012, p. 119).

\section{Metodologia}

\section{1. Área de estudo}

A bacia hidrográfica do Rio Brilhante está localizada na região sudoeste de Mato Grosso do Sul, ocupando uma área de $12.652 \mathrm{~km}^{2}$. A jusante da bacia, os rios Brilhante, Dourados e Vacaria formam a bacia do Rio 
Ivinhema, onde a bacia do Rio Brilhante sozinha corresponde a $27,2 \%$ da área total da bacia do Rio

Ivinhema. É composta por nove munícipios inseridos total ou parcialmente em seus limites (Angélica, Deodápolis, Douradina, Dourados, Itaporã, Maracaju, Ponta Porã, Rio Brilhante e Sidrolândia. A temperatura média anual dessa região hidrográfica oscila em torno de $23^{\circ} \mathrm{C}$. De acordo com a EMBRAPA (2005), as precipitações são superiores a $750 \mathrm{~mm}$ anuais, atingindo entre $1.400 \mathrm{e} 1.700 \mathrm{~mm}$. A precipitação média concentra-se no período que compreende a primavera e verão (outubro a março).

\subsection{Procedimentos}

A metodologia empregada foi baseada nos recursos geotecnológicos, envolvendo técnicas de aquisição, tratamento, armazenamento e análise espacial dos dados extraídos via SIG. Para tanto foram utilizados os softwares ArcGis ${ }^{\circledR} 10.2$ e QGIS 2.18 por meio do qual foi criado banco de dados georreferenciado. Em ambiente SIG foi possível a análise espacial integrada mediante a correlação entre as camadas. Além disso, pôde-se promover o cálculo da área e separação dos vetores referentes aos temas mapeados.

Por meio da ferramenta clip do ArcToolbox no ArcGis foram recortados os vetores da vegetação de interesse para a bacia em questão. Primeiramente identificou-se vegetação nativa da bacia - a partir dos dados do Macrozoneamento Geoambiental do MS para o ano de 1984 - e a cobertura vegetal em 2015 por meio do uso dos dados do IBGE. Posteriormente seguiu-se então para a reclassificação operando os registros diretamente na tabela de atributos de modo a classificá-los em apenas duas categorias: as áreas naturais e as áreas antrópicas.

O nível de detalhamento da escala espacial adotada para o mapeamento, implicou no estabelecimento de um modelo de classificação com a definição das seguintes classes temáticas que representam os tipos de vegetação e abrangem as seguintes classes: Floresta E. S. Aluvial, Floresta E. S. Submontana, Floresta E. S. Montana, Cerradão e Cerrado sentido restrito.

\section{Resultados e Discussão}

O mapa da cobertura vegetal da bacia no ano de 2015 apresenta os remanescentes da cobertura vegetal nativa e antrópica existentes. Foram identificadas cinco classes de vegetação na bacia hidrográfica em estudo:

- Floresta Estacional Semidecidual Aluvial: é encontrada em uma estreita faixa que ocupa as margens dos cursos d'água, sobretudo na parte alta da bacia do Rio Brilhante. A estrutura desta fitofisionomia é semelhante à da floresta ciliar de todos cursos de água, só diferente de acordo 
XVII Simpósio Brasileiro

de Geografia Física Aplicada

I Congresso Nacional

de Geografia Física
OS DESAFIOS DA GEOGRAFIA FÍSICA NA FRONTEIRA DO CONHECIMENTO

Instituto de Geociências - Unicamp

Campinas - SP

28 de Junho à 02 de Julho de 2017

com a posição geográfica (MATO GROSSO DO SUL, 2002). As áreas agrícolas têm a maior representatividade na área da bacia e o restante da área se apresenta com pastagem plantada.

- Floresta Estacional Semidecidual Submontana: são encontradas algumas formações desta classe nos municípios de Rio Brilhante, Sidrolândia, Itaporã e Angélica, porém se restringem a alguns poucos fragmentos isolados. No interior da bacia apenas o município de Dourados apresenta a formação da Floresta Estacional Semidecidual Montana, restrita a um fragmento na parte oeste próximo à fronteira com o município de Ponta Porã.

- Floresta Estacional Semidecidual Montana: As áreas ocupadas por esta formação florestal são poucas, já que tal tipo se estabelece acima de 500m de altitude. Na área de estudo ocorre em áreas relativamente pequenas ou situadas em pontos culminantes dos planaltos areníticos (IBGE, 2012). No interior da bacia apenas o município de Dourados apresenta esta formação, restrita a um fragmento na parte oeste próximo à fronteira com o município de Ponta Porã.

- Cerradão: na região da bacia do Rio Brilhante a cobertura vegetal original dominante era o Cerrado aberto denso (Cerradão), atualmente estas formações deram lugar às pastagens plantadas e lavouras, há poucas áreas onde pode ser encontrado o Cerrado original (MATO GROSSO DO SUL, 2011).

- Cerrado sentido restrito (Cerrado Denso, Cerrado Típico, Cerrado Ralo e Cerrado Rupestre): O Cerrado sentido restrito caracteriza-se pela formação natural ou antropizada é caracterizado pela presença de árvores baixas, inclinadas, tortuosas, com ramificações irregulares e retorcidas, sujeito ao fogo anual. $\mathrm{Na}$ área da bacia são encontrados dois grande blocos de vegetação desta classe, um em Ponta Porã e outro em Maracaju.

O acervo dos dados de vegetação tanto do IBGE quanto do Macrozoneamento do MS são compatíveis com a escala requerida para a reclassificação que se objetivou. Por meio do tratamento e análise espacial dos vetores obteve-se o mapeamento da cobertura vegetal nativa (primária ou secundária) para a área bacia do Rio Brilhante para o ano de 1984 (Figura 3). 


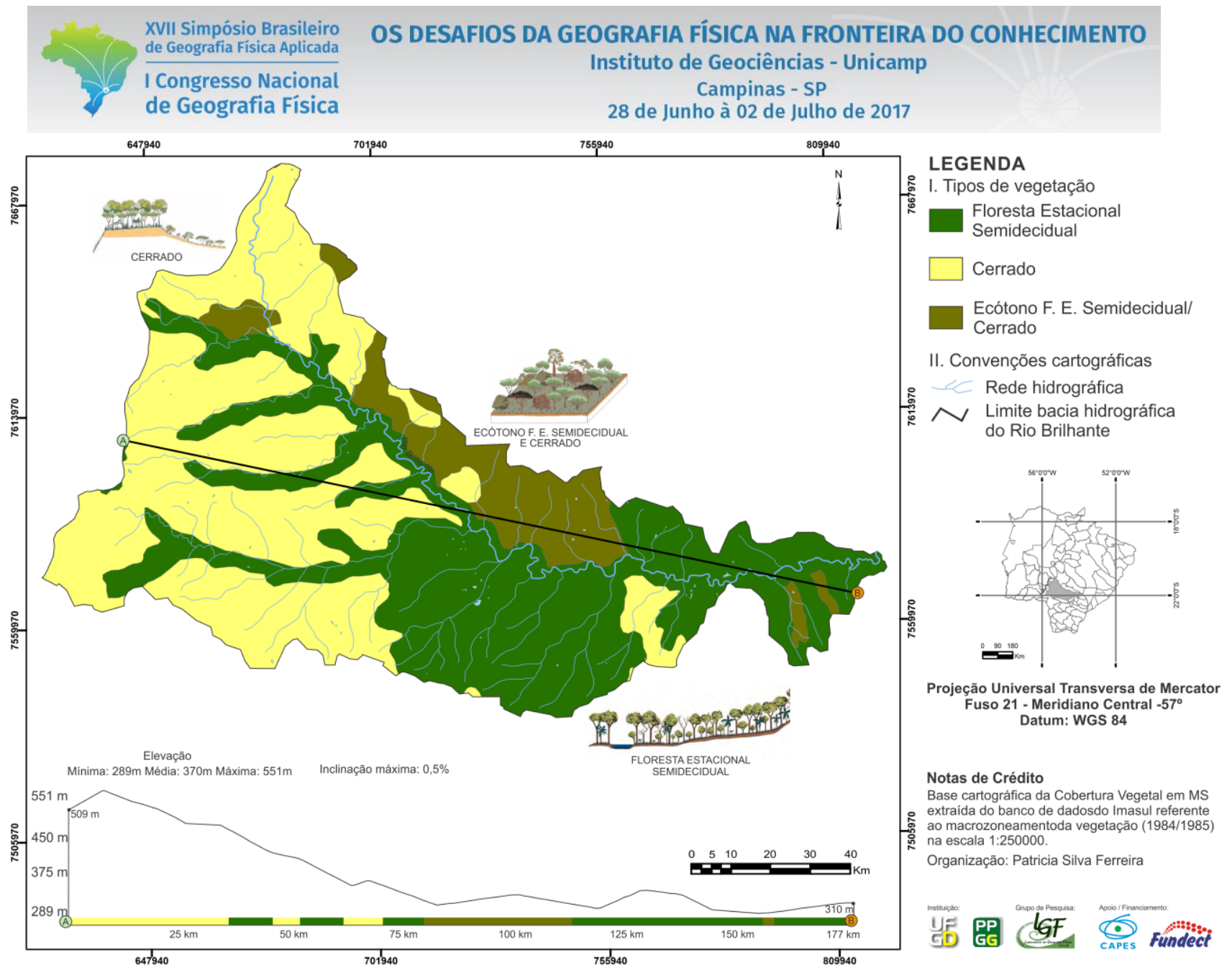

Figura 3 - Classificação da vegetação a partir dos dados do Macrozoneamento Geoambiental do MS para a bacia do Rio Brilhante.

O cálculo de área realizado por meio da tabela de atributos pela ferramenta Calculate Geometry do ArcGis indica que em 1984 a cobertura vegetal natural da bacia do Rio Brilhante era composta pelo Cerrado (46\%), pela Floresta Estacional Semidecidual (43\%) e o restante da área (11\%) abrangia a vegetação de contato entre essas duas fitofisionomias (Tabela I).

Tabela I - Quantificação dos diferentes tipos de vegetação nativa da bacia hidrográfica do Rio Brilhante em 1984.

\begin{tabular}{l|r|r}
\hline \multicolumn{1}{c|}{ Tipo de Vegetação } & Àrea $\left(\mathrm{Km}^{2}\right)$ & \multicolumn{1}{c}{$(\%)$} \\
\hline Floresta Estacional Semidecidual & 4.969 & 43 \\
\hline Cerrado & 5.295 & 45,9 \\
\hline Ecótono Floresta E. Semidecidual / Cerrado & 1.291 & 11,1 \\
\hline
\end{tabular}

Em seguida foram reclassificados e quantificados os vetores da cobertura vegetal natural para o ano de 2015 da bacia em estudo. 


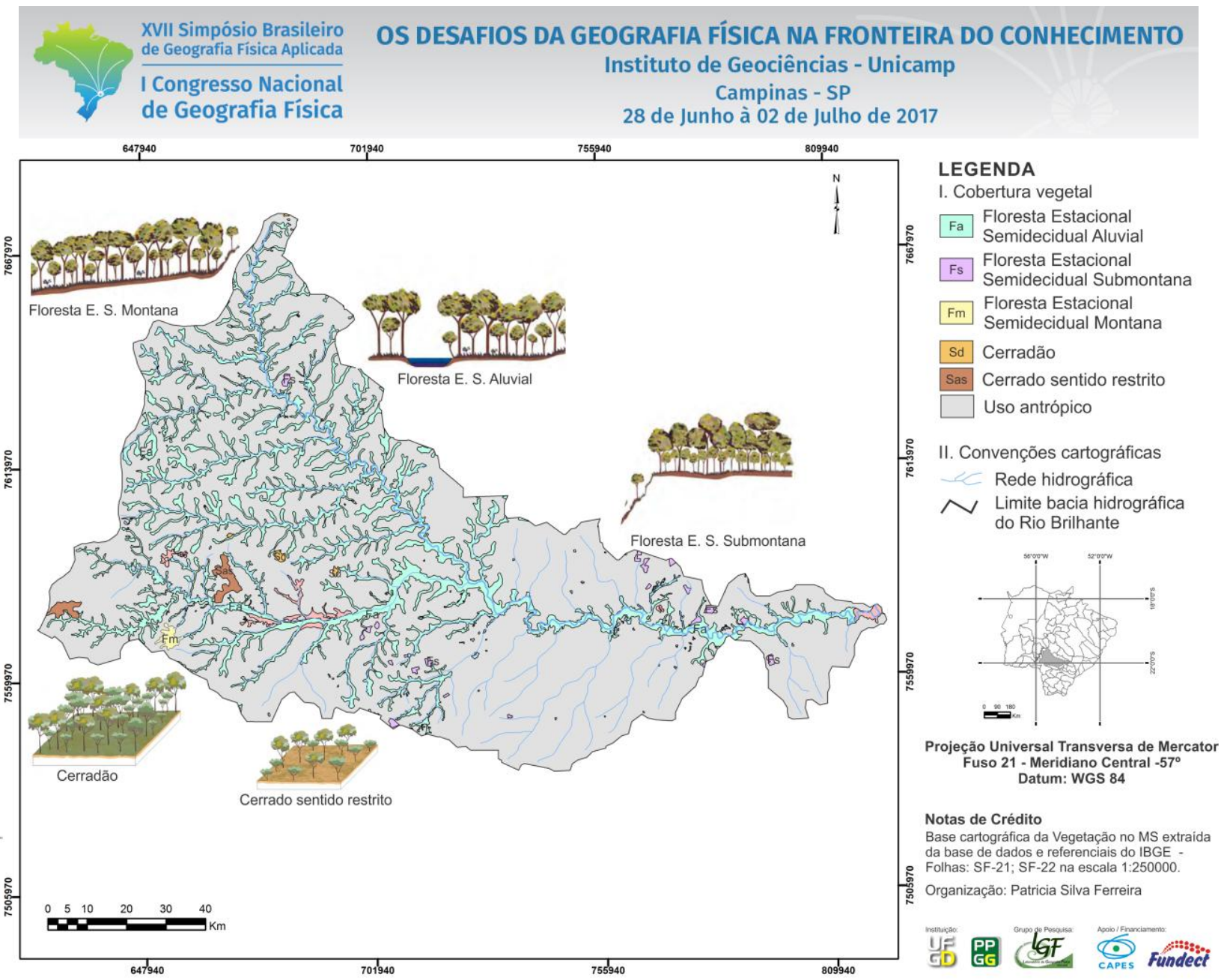

Figura 4 - Reclassificação da vegetação a partir dos dados do IBGE para a bacia do Rio Brilhante.

O cálculo de área para todas as categorias de cobertura vegetal revelam o predomínio da atividade agrícola $\left(7.079 \mathrm{~km}^{2}\right)$ seguida pela pecuária $\left(2.292 \mathrm{~km}^{2}\right.$ ) (Figura 5) no interior na bacia do Rio Brilhante, contrapondo-se a uma pequena parcela de fragmentos de vegetação natural, representados pelos remanescentes da Floresta Estacional Semidecidual e do Cerrado (Tabela II). Pode-se constatar que esta redução de áreas preservadas está associada ao histórico processo de ocupação que foi marcado pela introdução de práticas de manejo do solo, que promoveram radicalmente uma transformação no uso da terra, sobretudo nas últimas três décadas por meio de supressão vegetal para introdução de pastagens para criação de gado e para o cultivo agrícola.

Tabela II - Cobertura vegetal da bacia hidrográfica do Rio Brilhante em 2015

\begin{tabular}{l|r|c}
\hline \multicolumn{1}{c|}{ Cobertura vegetal } & Àrea $\left(\mathrm{Km}^{2}\right)$ & $(\%)$ \\
\hline Floresta E. S. Aluvial & 1.855 & 16,1 \\
\hline Floresta E. S. Montana & 19,13 & 0,16 \\
\hline Floresta E. S. Submontana & 38,16 & 0,33 \\
\hline Cerradão & 53,14 & 0,46 \\
\hline Cerrado sentido restrito & 9,53 & 0,08 \\
\hline Formação pioneira & 73,27 & 0,63 \\
\hline Uso antrópico & 9.442 & 82,1 \\
\hline
\end{tabular}




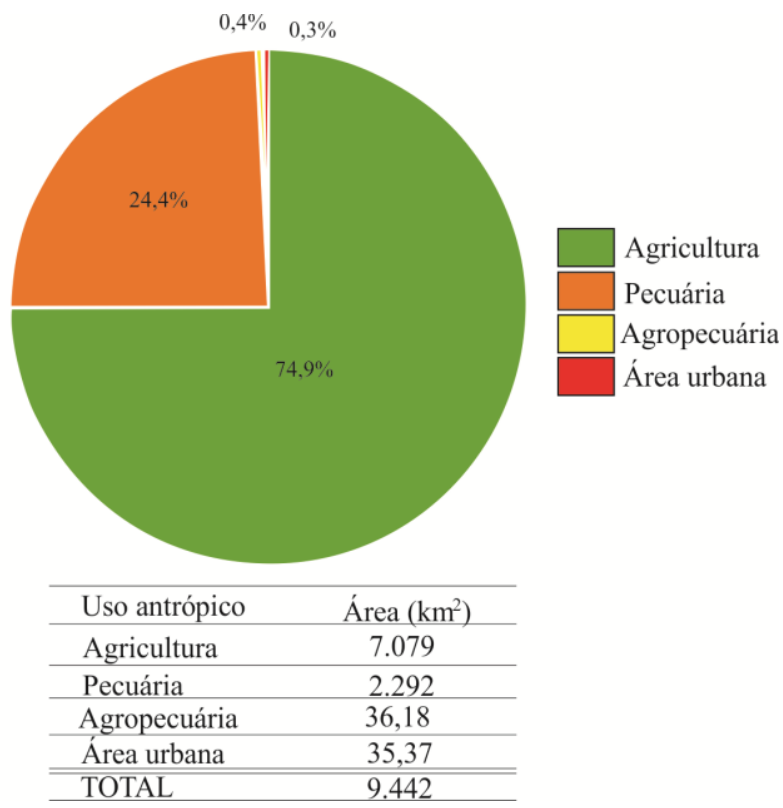

Figura 5 - Gráfico do uso e cobertura antrópica para a bacia do Rio Brilhante.

Áreas de vegetação mais densa estão associadas as APP, são remanescentes florestais compostos por resquícios da Floresta Estacional Semidecidual Aluvial formada por espécies de médio a grande porte estrutural, predominante ao longo das nascentes, lagos e cursos d'água.

Considerando a exigência do Código Florestal em vigor de que cada propriedade rural tenha um mínimo de $20 \%$ de sua área conservada sob o regime de uso estabelecido nessa Lei, se a bacia hidrográfica do Rio Brilhante fosse tomada como uma única propriedade, espera-se, uma vez cumprindo-se a lei, que a bacia tenha no mínimo, um valor próximo aos $20 \%$ do seu território coberto por áreas naturais mais as áreas de APP. Neste sentido, a bacia do Rio Brilhante apresenta um passivo ambiental, sobretudo no seu médio e baixo curso, onde é possivel observar extensas áreas de uso antrópico (seguramente várias propriedades com passivos de RL) e déficit de APP.

\section{Considerações Finais}

A bacia do Rio Brilhante apresenta potencial possibilidade para intensificação da atividade antrópica já que a mesma se encontra na rota da expansão das atividades agropecuárias, motivada principalmente pelas condições físicas favoráveis desta unidade hidrográfica constituída, principalmente de um relevo basicamente plano e de baixa declividade, associada às características físico-estruturais do Latossolo Vermelho. 
Estas características levaram a bacia do Rio Brilhante a se configurar como grande atrativo à agricultura mecanizada. A influência desses fatores na promoção de transformações do uso e cobertura das terras no interior dessa bacia é premente para um período de curto a médio prazo. $\mathrm{O}$ uso de ferramentas de geotecnologias foi fundamental para a realização da reclassificação da vegetação da área em estudo, pois permitiu o mapeamento, ora apresentado, com eficiência e baixo custo.

\section{Agradecimentos}

À Capes e a FUNDECT pelo apoio financeiro para desenvolvimento desta pesquisa.

\section{Bibliografia}

BRASIL. Lei Federal $\mathbf{N}^{\mathbf{0}}$ 12.651, de 12 de maio de 2012. Dispõe sobre a proteção da vegetação nativa; altera as Leis nos 6.938, de 31 de agosto de 1981, 9.393, de 19 de dezembro de 1996, e 11.428, de 22 de dezembro de 2006; revoga as Leis nos 4.771, de 15 de setembro de 1965, e 7.754, de 14 de abril de 1989, e a Medida Provisória no 2.166-67, de 24 de agosto de 2001; e dá outras providências. Disponível em: < http://www.planalto.gov.br/ccivil_03/_ato2011-2014/2012/lei/112651.htm>. Acesso em: 20 de fev/ 2017.

ENVIRONMENTAL SYSTEMS RESEARCH INSTITUTE (ESRI). Software ArcGIS Professional GIS for the desktop, version 10.2.2, 2014.

EMPRESA BRASILEIRA DE PESQUISA AGROPECUÁRIA (EMBRAPA). Precipitação esperada na Bacia do Rio Brilhante, MS. Dourados, MS, Embrapa/ Embrapa Agropecuária Oeste, 2005.

GANDOLFI, S. Impacto das Mudanças do Código Florestal. Laboratório de Ecologia e Restauração Florestal Departamento de Ciências Biológica - LERF - ESALQ/USP.

INSTITUTO BRASILEIRO DE GEOGRAFIA E ESTASTÍSTICA (IBGE). Introdução ao processamento digital de imagens. Rio de Janeiro: IBGE, Manuais Técnicos em Geociências, 2000.

$2012.271 \mathrm{p}$

Manual Técnico da Vegetação Brasileira. Rio de Janeiro: IBGE, Manuais Técnicos em Geociências,

MATO GROSSO DO SUL. Zoneamento Ecológico Econômico do Estado de Matogrosso do Sul (2002). Disponível em: http://www.semac.ms.gov.br/zeems/. Acesso em 21 de fev/2017.

Secretaria de Estado de Meio Ambiente, do Planejamento, da Ciência e Tecnologia. Caderno Geoambiental das Regiões de Planejamento do MS. Campo Grande, 2011.

QUANTUM GIS DEVELOPMENT TEAM, 2015. Quantum GIS Geographic Information System. Open Source Geospatial Foundation Project,Versão 2.12.3 "Lyon". Disponível em: http://qgis.osgeo.org.

RIBEIRO, J. F.; WALTER, B. M. T. Fitofisionomias do bioma Cerrado. In: SANO, S. M.; ALMEIDA, S. P. (ed.). Cerrado: ambiente e flora. Planaltina: Embrapa Cerrados, 1998.

SILVA, J. X.; ZAIDAN, R. T. (orgs.). Geoprocessamento e Análise ambiental: aplicações. Rio de Janeiro: Bertrand Brasil, 2004. 